\title{
Induction of in vitro propagation in mature embrios of maize
}

\author{
B.M.H. Humood*, O.I. Yudakova \\ Saratov State University, Saratov, Russia
}

DOI 10.18699/ICG-PlantGen2019-48

(c) Autors, 2019

*e-mail: bobogold18@gmail.com

\begin{abstract}
An efficient and reproducible regeneration protocol via direct organogenesis has been established using mature embryos as explants for three maize lines: BM (Brown marker), AT-TM (bm, wx, y) and AT-TM (lg, y). The seeds were sterilized by 'Domestos', $70 \%$ ethyl alcohol and $0.1 \%$ mercuric chloride. The different mediums for initiation, micropropagation and rooting were tested. The best results were obtained on MS medium supplemented with $2.0 \mathrm{mg} / \mathrm{l} \mathrm{BAP}$. The 3-5 axillary shoots developed in the basal parts of the explant after 3-4 weeks of cultivation. Microshoots were elongated on MS medium supplemented with $0.2 \mathrm{mg} / \mathrm{l}$ BAP. Microshoots in length were rooted on MS medium without hormones.

Key words: clonal micropropagation; in vitro cultivation; mature embryo culture; direct organogenesis; maize; Zea mays.
\end{abstract}

\section{Introduction}

Maize is one of the important food, feed and industrial plants. Breeding new varieties adapted to different environmental condition is necessary for practical use of maize and expanding its production. Particularly relevant is the breeding of new highly productive and environmentally plastic varieties and lines for growing in temperate latitudes, since their genetic diversity is limited.

Biotechnological and genetic engineering methods can significantly accelerate the selection process. Plant regeneration in vitro can occur both through direct organogenesis and through callus cultures with the subsequent development of de novo embryoids and shoots. Regeneration through callus cultures is often accompanied by somaclonal variability, which is undesirable when cloning unique genotypes and carrying out genetic engineering research. Plant regeneration through direct organogenesis, eliminating the stage of callus formation, can minimize the risk of somaclonal variability. Currently, considerable experience has been accumulated in the induction of somatic embryogenesis in maize when the explants are represented by immature and mature embryos (Huang, Wei, 2004; Rakshit et al., 2010; Joshi et al., 2014), unfertilized ovaries (Alatortseva, Tyrnov, 2003), fertilized ovules (Tang et al., 2006), anthers (Obert et al., 2004), seedling segments (Santos et al., 1984), leaves (Ahmadabadi et al., 2007), etc. However, induction of direct organogenesis was performed only for single genotypes (Mushke et al., 2016; Ahmad et al., 2017; Ovchinnikova et al., Humood et al., 2018; Olawuyi et al., 2019). It is known that the ability of regeneration in vitro largely depends on the plant genotype. It is believed that in maize only a small number of genotypes have regenerative capacities (Armstrong, Green, 1985). In this connection, the search for a new maize genotypes "responsive" to the in vitro culture and the induction of direct organogenesis in them is relevant.

The objective of the present study was to induce a direct organogenesis from mature embryos of maize.

\section{Materials and methods}

The materials of the present study are maize lines: BM (Brown marker), AT-TM (bm, wx, y) and AT-TM (lg, y). Lines AT-TM (bm, wx, y) and AT-TM (lg, y) were developed at the Saratov State University (Gutorova et al., 2016).

The mature embryos were used as primary explants. The seeds were soaked in distilled water for 24 hours and surface- sterilized with 'Domestos', $70 \%$ ethyl alcohol and $0.1 \%$ mercuric chloride for $5 \mathrm{~min}$ and rinsed four times with double distilled water. Embryos were isolated from the seeds and transferred onto nutrient medium for initiation of a sterile culture. The following media were tested: 1) starvation agar; 2) Murashige-Skuga (MS) (Murashige, Skoog, 1962) with the addition of vitamins according to the prescribed medium, $20 \mathrm{mg} / \mathrm{l}$ sucrose, $7 \mathrm{~g} / \mathrm{l}$ agar (PanReac), without the addition of hormones; 3) MS supplemented with $0.5 \mathrm{mg} / 1$ 6-benzylaminopurine (BAP). MS medium supplemented with different concentrations of BAP $(0.5$ and $2.0 \mathrm{mg} / \mathrm{l})$ were used for micropropagation. The medium was autoclaved for $20 \mathrm{~min}$ at $120^{\circ} \mathrm{C}$. The cultures were maintained at $24{ }^{\circ} \mathrm{C}$ under a $16-\mathrm{h}$ photoperiod in the Sanyo MLR-352 climatic chamber.

Statistical processing of the results was carried out using Microsoft Office Excel 2010 and AGROS programs.

\section{Results and discussion}

Isolated embryos germinated with a frequency of about $90 \%$ in all approved variants of medium. However, vitrification of seedling tissues took place on starvation agar. Various morphoses (coleoptile underdevelopment, leaf curling and others) were observed on the medium supplemented with $0.5 \mathrm{mg} / \mathrm{l} \mathrm{BAP}$. Normal viable seedlings were obtained only on MS medium without hormones.

Seedlings after 7 days of cultivation were transferred to MS medium with 0.5 or $2.0 \mathrm{mg} / 1 \mathrm{BAP}$. The frequency of explant survival was 55.4, 40.6 and $92.0 \%$ in lines BM, ATTM (bm, wx, y) and AT-TM (lg, y), respectively. An effect of the genotype on the survival of the explants was revealed. 
$a$

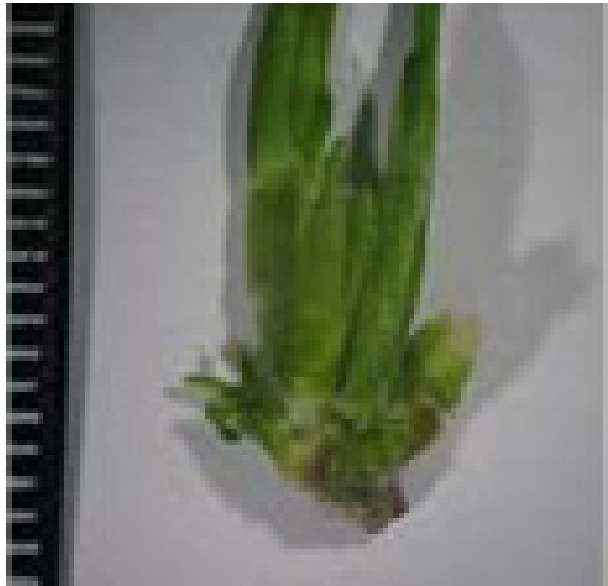

$c$

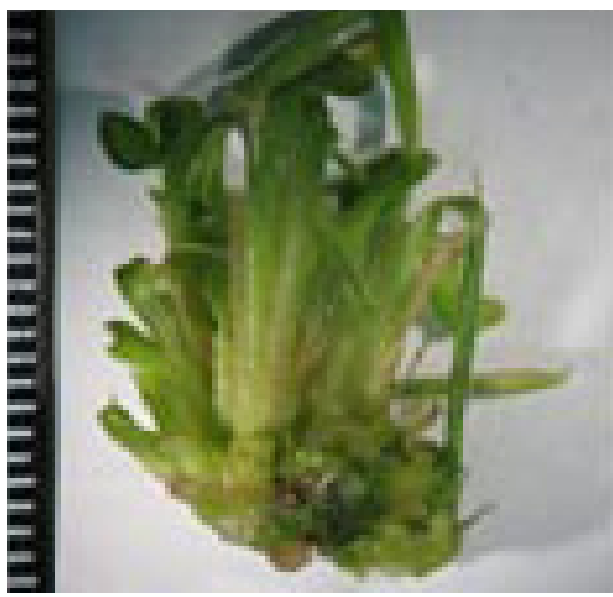

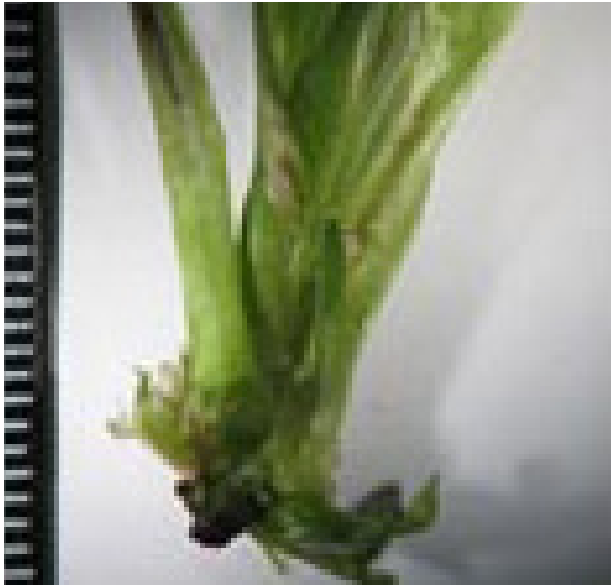

$d$

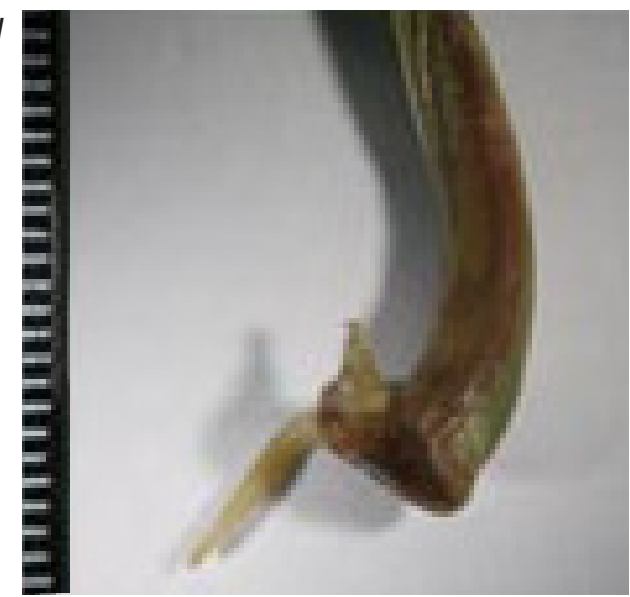

Figure 1. Regenerants of maize line AT-TM (bm, wx, y). a-c: on MS medium with $2.0 \mathrm{mg} / \mathrm{l} \mathrm{BAP}$ after $3(a), 4(b)$ and 5 (c) weeks of cultivation; $d$ : a shoot with spontaneously developed roots on MS medium with $0.2 \mathrm{mg} / \mathrm{l} \mathrm{BAP}$ after 10 days of cultivation.

Callus did not form both on medium supplemented with $0.5 \mathrm{mg} / \mathrm{l}$ and $2.0 \mathrm{mg} / \mathrm{l}$ BAP. Seedling after 3-4 weeks of cultivation on MS medium with $0.5 \mathrm{mg} / 1 \mathrm{BAP}$ consisted of several short internodes and 4-5 leaves. From 1 to 3 axillary buds were found in the node after the leaves were removed from the seedling. Axillary buds germinated in shoots after 5-7 weeks of cultivation. They had a length of 2-3 mm and were usually covered with a sheet vagina. In this regard, the explant visually looked like one primary shoot.

The process of axillary shoot formation was accelerated on MS medium with $2.0 \mathrm{mg} / \mathrm{l} \mathrm{BAP}$. The buds were formed in the first and second weeks of cultivation. Axillary shoots developed after 3-4 weeks of cultivation (Figure 1, $a, b$ ). Their number increased to 3-5. Regenerants looked like bundles of shortened shoots after 5 weeks of cultivation (Figure 1,c). The axillary shoot reached $10-15 \mathrm{~mm}$ in length.

The explants were transferred to MS medium without hormones or MS with $0.2 \mathrm{mg} / \mathrm{l} \mathrm{BAP}$ for elongation of axillary shoots. Microshoots did not lengthen and turned yellow on medium without hormones. The elongation of the shoots was observed only on MS medium with $0.2 \mathrm{mg} / \mathrm{l} \mathrm{BAP}$. This made it possible to separate shoots and transfer them on MS medium supplemented with auxins for rooting. It should be noted that some shoots spontaneously rooted on MS medium with $0.2 \mathrm{mg} / 1$ BAP (Figure 1, $d$ ).

\section{Conclusions}

Thus, we successfully carried out the induction of direct organogenesis for three maize genotypes. Previously successful induction of direct shoot organogenesis in some maize lines was carried out using BAP in combination with other hormones (IAA, $\mathrm{GA}_{3}$ ) (Ahmad et al., 2017). BAP is one of the most important cytokinins which play an important role in the multiplication and micropropagation of the plants. Only BAP was sufficient for shoot multiplication in the lines studied by us. The absence of the effect of the genotype on the number of developing axillary shoots and the influence of BAP concentration in the medium on this indicator were established.

The results obtained open up prospects for the use of the developed technology in gene engineering studies with the lines studied.

\section{References}

Ahmad M.Z., Hussain I., Ahmed S., Roomi S. Direct in vitro multiple shoot regeneration in maize (Zea mays) inbred lines. J. Innov BioRes. 2017;1(1):24-29. 
Ahmadabadi M., Ruf S., Bock R. A leaf-based regeneration and transformation system for maize (Zea mays L). Transgenic Res. 2007;16: 437-448. DOI 10.1007/s11248-006-9046-y.

Alatortseva T.A., Tyrnov V.S. Hormone-independent manifestation of in vitro embryogenesis in parthenogenetic maize lines. Bulletin Botanical Garden Saratov State University. 2003;2:207-211. (in Russian)

Armstrong C., Green C.E. Establishment and maintenance of frible, embryogenic maize callus and involvement of L-proline. Planta. 1985;164(2):207-214.

Gutorova O.V., Apanasova N.V., Yudakova O.I. Creation of genetically marked maize lines with inherited and induced types of parthenogenesis. Izv. Samara Scientific Center Russian Academy Sci. 2016;1(2-2):341-344. (in Russian)

Huang X.Q., Wei Z.M. High-frequency plant regeneration through callus initiation from mature embryos of maize (Zea mays L.). Plant Cell Rep. 2004;22:793-800. DOI 10.1007/s00299-003-0748-9.

Humood B.M.H., Apanasova N.V., Yudakova O.I. Introduction to culture in vitro of corn parthenogenetic lines. Izv. Saratov Univ. (N.S.), Ser. Chemistry. Biol. Ecol. 2018;18(3):320-324. DOI 10.18500/ 1816-9775-2018-18-3-320-324. (in Russian)

Joshi J.B., Yathish K.R., Amalraj J.J., Kumar K.K., Kokiladevi E., Arul L., Gnanam R., Balasubramanian P., Sudhakar D. A highthroughput regeneration protocol for recalcitrant tropical Indian maize (Zea mays L) inbreds. Maydica Electronic Publication. 2014; 59:211-216.

Murashige T., Skoog F. A revised medium for rapid growth and bioassays with tobacco tissue cultures. Physiol. Plant. 1962;1(15):473497. DOI 10.1111/J.1399-3054/1962.TB08052.X.

Mushke R., Yarra R., Bulle M. Efficient in vitro direct shoot organogenesis from seedling derived split node explants of maize (Zea mays L.). J. Genet. Engineering Biotechnol. 2016;14:49-53. DOI 10.1016j.jgeb.2016.03.001.

Obert B., Barnabas B. Colchicine induced embryogenesis in maize. Plant Cell Tiss. Org. Cult. 2004;77:283-285. DOI Doi.org/10.1023/ B:TICU.0000018399.60106.33.

Olawuyi O.J., Dalamu O., Olowe O.M. In vitro regeneration and proliferation of maize (Zea mays L.) genotypes through direct organogenesis. J. Natural Sci. Research. 2019;9(6):65-73.

Ovchinnikova V.N., Sotchenko V.S., Sotchenko Y.V. et al. Susceptibility of maize mesocotyl culture to agrobacterium transformation and its in vitro regeneration. Appl Biochem Microbiol. 2018;54(8): 808-815. DOI 10.1134/S0003683818080057.

Rakshit S., Rashid Z., Sekhar J. C., Fatma T., Dass S. Callus induction and whole plant regeneration in elite Indian maize (Zea mays L) inbreds. Plant Cell Tiss. Org. Cult. 2010;100(1):31-37. DOI 10.5897/ AJB10.500.

Santos M.A., Torne J.M., Blanco J.L. Methods of obtaining maize totipotent tissue. I. Seedling segments culture. Plant Sci Lett. 1984; 33:309-315.

Tang F., Tao Y., Zhao T., Wang G. In vitro production of haploid and doubled haploid plants from pollinated ovaries of maize (Zea mays). Plant Cell Tiss. Org. Cult. 2006;84:233-237. DOI 10.1007/s11240010-9874-6.

Acknowledgements. The work is supported by the Ministry of Education and Science of Russia within the framework of the basic part of the state task in the sphere of scientific activity on the assignment no. 6.8798.2017/BCh.

Conflict of interest. The authors declare no conflict of interest. 